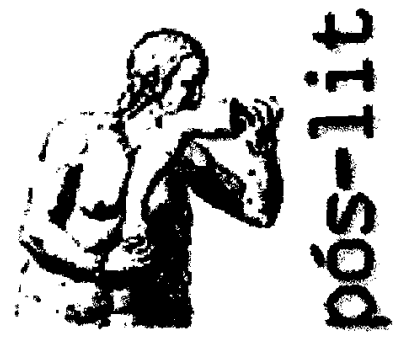

Programa de Pós-Graduação em Letras: Estudos Literários da Faculdade de Letras da UFMG

Artigo disponível em http://www.letras.ufmg.br/poslit

\section{O FEDRO DE PLATÃO NA LETTURA DE JACQUES DERRIDA}

Edson Rosa da Silva UFRJ

\section{RÉSUMÉ}

Cet article discute le texte de Jacques Derrida, «La pharmacie de Platon», où il analyse le mythe platonicien qui décrit la naissance de l'écriture dans le Phèdre. Celle-ci est vue comme le pharmakon, non le remède capable de seconder la mémoire, mais le poison, la déviation qui introduit l'ambiguïté, le glissement des sens, la possibilité inépuisable d'autres lectures. 
Ao refletir sobre a forma como começaria este artigo, como introduziria a reflexão de Derrida a propósito da obra de Platão, depareime com duas citações que poderiam, creio eu, dar origem à minha discussão, ou melhor dizendo, poderiam ser o pretexto, ou ainda, destacando o prefixo, citações que poderiam ser o pré-texto do meu texto.

Assim, entro já, e sem rodeios, no jogo textual, ao qual sucumbimos todos, voluntária ou involuntariamente, quando incorremos no risco da escritura ou da leitura. Risco esse ao qual, nós, professores de letras, críticos e escritores, estamos constantemente expostos. E, ainda mais grave, risco do qual gostamos. Por isso, poderia até renomear este artigo: "o risco iminente e sedutor do texto".

Parece-me, pois, que a consciência desse risco acha-se claramente presente nas citações que escolhi para começar esse diálogo, não só entre Platão e Derrida, como também, e sobretudo, entre os possíveis textos que, a partir daí, se engendraram e se vão agora engendrar, formando, desse modo, o contexto nunca decidivel (para usar uma palavra característica de Derrida) em que nos colocam a cultura e a grande biblioteca que nos precedem.

A primeira delas é uma pequena citação de Nietzsche que Jacques Derrida coloca em epígrafe ao capítulo primeiro da Gramatologia (1967): "Sócrates, aquele que não escreve». E a outra é um trecho de uma carta de Platão, que diz:

[...] A maior preocupação será não escrever, mas aprender de cor, pois é impossível que os escritos não acabem por cair no domínio público. Por isso, para a posteridade, eu mesmo não escrevi sobre tais questões. Não há obra de Platão e jamais haverá uma. O que atualmente se designa sob esse nome é de Sócrates, no tempo de sua bela juventude. Adeus e obedece-me. Tão logo tenhas lido esta carta, queima-a. ${ }^{2}$

Da primeira citação, não se pode contestar a verdade. Sabemos que Sócrates - que viveu de 470 a 399 a.C. - dedicou a sua vida à educação dos jovens atenienses, ensinando e discutindo nas ruas, nos ginásios e nos banquetes, sem jamais ter escrito. Quanto à segunda, entretanto, como entendê-la? Platão - que viveu de 428 a 348 a. C. e foi discípulo de Sócrates

1. DERRIDA, 1967. p. 15. Foi publicado em português cam o título Gromatologio, pela Editoro da Universidade de São Poulo, em

2. Carta $11,314 c$. de 408 a 399 - redigiu e publicou os ensinamentos do mestre sob a forma de diálogos a partir de 387 a. C. Por que razão negar a própria obra? Se, por um lado, quisermos ver aí uma prova da modéstia de Platão e um culto de devoção ao mestre, não acharemos argumentos no texto. Se quisermos, porém, analisar o medo ou a precaução de Platão quanto à interpretação futura de seus textos, para tal não faltariam indícios nesse trecho da carta. "Escrever" parece ao filósofo grego «a maior preocupação», já que os escritos acabam sempre por cair no domínio público. A razão poderia até ser contestada. Por que não gostaria que os escritos caíssem no domínio público? Não é justamente o que mais se deseja: que o público conheça e comente as idéias de um escritor? A História nos mostra que todas as leis, tratados e acordos, tudo aquilo, enfim, cuja interpretação se quer perenizar deve figurar "preto no branco". Por que motivo, então, afirma Platão que é melhor "aprender de cor» do que «escrever»? E, mais ainda, por que ordena ao seu destinatário que «queime» a carta depois de a ter lido? Por que razão a reprodução oral, quando se aprende de cor, é mais apropriada do que a inscrição daquilo que se pensa e se ouve?

As questões que lanço constituem a base da reflexão que Jacques Derrida, filósofo francês, nascido em 1930, professor da École des Hautes Études en Science Sociale, em Paris, faz sobre a escrita em toda a sua obra. Embora possa fazer referências a diversos livros, pretendo discutir sobretudo o texto intitulado "A farmácia de Platão", publicado pela primeira vez na revista Tel Quel, $\mathbf{n}^{\text {os }} 32$ e 33, em $1968^{3}$

Por que escolhi o Fedro e não um outro diálogo? Primeiramente, por que é um dos diálogos mais importantes de Platão, em seguida porque é considerado por certos críticos como um texto mal organizado, e, por fim, e sobretudo, porque é o diálogo que trata do nascimento da escrita. Dessa forma, fazendo interagir a voz de Platão e a de Derrida, acredito poder trazer, para aqueles que, porventura, desconhecem a análise do filósofo francês, uma contribuição para a leitura desse texto de Platão.

O Fedro divide-se da seguinte forma:

1. Prólogo: o encontro de Sócrates e de Fedro, e a descrição do cenário da conversa

2. O discurso de Lísias sobre o amor

3. Intermédio com observações sobre a forma e o fundo do discurso.

3. Publicado posteriormente em DERRIDA, 1972. p. 69-196. 
4. Críticas sobre o fundo do discurso de Lísias

4.1 - O primeiro discurso de Sócrates: discussão sobre o amor

4.2 - O segundo discurso de Sócrates: elogio da loucura

5. Críticas sobre a forma do discurso de Lísias

5.1 - A arte de falar

5.2 - A escrita

6. Conclusão geral com uma prece ao deus Pã.

É sobre o tema do nascimento da escrita, a última parte do discurso de Sócrates, que incide a análise de Jacques Derrida. Este começa por mostrar que, embora a escrita seja a última parte do discurso, não se trata de um apêndice ao diálogo. A escrita constitui, ao invés, um fio condutor que atravessa o texto de ponta a ponta. Assim, vários momentos da discussão preparam o relato do mito de Theuth, mito do nascimento da escrita.

Com efeito, Derrida chama nossa atenção para o fato de o texto de Platão fazer várias alusões ao ato de escrever. Refere-se aos logógrafos, que redigiam discursos para outras pessoas, textos lidos na ausência de seus autores, como também ao discurso de Lísias sobre o amor, que escrito e enrolado, é transportado por Fedro para ser lido para Sócrates. Derrida observa, ainda, que o que faz Sócrates deixar o espaço da cidade, onde habitualmente ensina, para ir ao campo em companhia de Fedro, são os textos escritos, os biblia, que contêm o discurso de Lísias. Acentua, dessa forma, que a mola do texto não é o tema da discussão - o amor - , mas a importância do texto escrito - veículo da palavra. Finalmente, concentrase na análise da mito de Theuth. Eis o texto:

SÓCRATES: Mas convém ou não escrever? Em que condições fica bem fazê-lo, e em que outras, não? Eis uma questão sem resposta. Não é?

FEDRO: Sim.

SÓCRATES: Pois bem, tu sabes como, em matéria de discurso, deves fazer e falar para agradar o mais possivel a deus.

FEDRO: Não. E tu?

SÓCRATES: Sou capaz, em todo caso, de contar alguma coisa que ouvi dos antigos. Ora, são eles que conhecem a verdade. Se pudéssemos encontrá-la sozinhos, será que ainda nos preocuparíamos com as crenças da humanidade?

FEDRO: Que pergunta estranha! Vamos, conta o que dizes ter ouvido. SOCRATES: Pois bem! Ouvi contar que, próximo a Naucrates, no Egito, há uma das antigas divindades cujo emblema sagrado é um pássaro que chamam, bem sabes, de ibis; o nome do deus é Theuth. pássaro que chamam, bem sabes, de ibis; o nome do deus é Theuth.
Foi ele, pois, o primeiro a descobrir o número e o cálculo, a geometria e a astronomia, e também o jogo do gamão e os dados, e enfim, e sobretudo, os caracteres da escrita (grámmata). Ora, naquele tempo, reinava sobre todo o Egito Tamus, que residia na grande cidade da região alta, que os gregos chamam de Tebas do Egito, assim como chamam, ao deus Tamus, Amon. Theuth, tendo vindo encontrá-lo, mostrou-lhe suas artes, dizendo-lhe, que era preciso comunicá-las aos demais egípcios. Tamus, entretanto, perguntou-lhe qual poderia ser a utilidade de cada uma daquelas artes; e, enquanto Theuth dava explicaçōes, Tamus, conforme as julgasse bem ou mal fundadas, as elogiava ou as criticava. Numerosas foram com certeza, diz-se, as observaçōes que, sobre cada arte, Tamus fez a Theuth em todos os observaçoes que, sobre cada arte, Tamus fez a Theuth em todos os
sentidos: sua relação detalhada exigiria um longo discurso. Mas, chegada a vez da escrita, diz Theuth: "Eis aqui, ó rei, o saber que oferecerá aos egípcios mais saber, mais ciência e mais memória; o remédio da ciência e da memória foi encontrado". Mas Tamus replicou: "Ó Theuth, maior mestre das artes, aquele que pode gerar uma arte não é aquele que pode fazer o julgamento das desvantagens e da utilidade para os que dela se devem servir. $E$ eis que tu, que és o pai da arte de escrever, queres atribuir-lhe, por complacência, um poder que é o oposto daquele que ela possui. Com efeito, essa arte provocará o esquecimento naqueles que a praticarem, pois deixarão de exercer a memória: com efeito, depositando sua confiança na escrita, é de fora, graças a marcas estranhas ao homem, e não de dentro, graças a eles mesmos, que farão ato de rememoração; não é, portanto, o remédio da memória que achaste, mas o da rememoração. Quanto à ciência, é o simulacro que estás propondo aos teus discípulos, não a realidade. Portanto, logo que, graças a ti, tiverem ouvido falar de muitas coisas, sem que tenham recebido seu ensinamento, parecerão ter muita ciência, enquanto que, na maioria dos casos, não terão nenhuma; ademais, serão insuportáveis no trato, pois que se terão tornado simulacros de sábios, ao invés de serem sábios. ${ }^{4}$

Derrida retira desse texto alguns aspectos capitais que busca interpretar: o poder do logos - a palavra do Rei que julga e determina - e a força do phármakon - o presente, remédio ou veneno, que Theuth oferece a Tamus.

Ao abordar, já em De la grammatologie, a questão do fonocentrismo - a presença do emissor da mensagem estreitamente ligada à sua fala, à sua phoné - Derrida alia fonocentrismo e logocentrismo, colocando-os no âmago de uma concepção metafísico-teológica do mundo. $\mathrm{O}$ som - a imagem acústica de que fala Saussure - remete sempre para uma presença que garante a justeza dos sentidos expressos. Quem falou garante o que quis

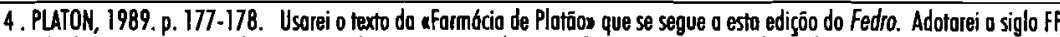

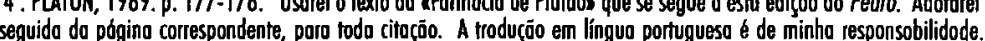

REVISTA DEE ESTUDOS DE LTERATURA 
dizer. Não há como escapar àquela verdade. Só quem falou pode afiançar o que disse. Referindo-se a essa íntima ligação do significante com o significado, Derrida diz: "Ela se instala, pois, na descendência desse logocentrismo que é também um fonocentrismo: proximidade absoluta da voz e do ser, da voz e da idealidade do sentidom."

Derrida identifica, na figura do deus Tamus, as figuras do rei e do pai, atribuindo, assim, a origem e o poder da palavra, precisamente do logos, à posição paterna. "Não que isso se produza somente e por excelência em Platão", diz o escritor francês, mas "o 'platonismo' o ilustra com um brilho e uma sutileza incomparáveis» (FP, 273).

O logos é, pois, um filho que se destruiria sem a presença do pai. Do pai que responde. Que responde por ele e o defende. Sem o pai, não é mais que uma escrita. (FP, 273)

Nesse sentido, a escrita, enquanto transcrição gráfica da palavra do pai, é vista por Platão como secundária e inferior, como filha bastarda. O logos é o saber vivo; o livro - conjunto de saberes acumulados e guardados pela palavra escrita - é um simulacro de saber. Por isso, diz Tamus que os discípulos de Theuth "parecerão ter muita ciência, enquanto que, na maioria dos casos, não terão nenhuma", já que terão aprendido de cor "as histórias acumuladas, as nomenclaturas, as receitas e as fórmulas". Ou seja: terão lido o saber escrito; não terão ouvido a palavra do mestre, porta-voz da verdade e da ciência, a única forma, pelo que se depreende do discurso de Tamus, de se transmitir um saber vivo e verdadeiro. Por isso, a ciência de quem lê é um simulacro; só quem se locupleta do verbo divino é realmente sábio.

Um segundo elemento desse trecho do diálogo explorado por Derrida é o conceito de phármakon. Quando Theuth apresenta os caracteres da escrita a Tamus, diz que "o remédio da ciência e da memória foi encontradom, o phármakon da ciência e da memória. Tamus, que representa Amon, o deus dos deuses, rejeita a oferenda, e rebaixa o phármakon, já que ele, Tamus, é o rei-que-fala, que não sabe escrever e, portanto, suspeita da escrita e a vigia. Mas a análise de Derrida vai mais longe.

Para ele, a palavra phármakon está envolvida numa rede de significações. Dentro da língua, um jogo se estabelece entre as diversas funções da palavra, e, na palavra, entre diversos sedimentos ou diversas

5. Op. ait.p. 23. regiōes da cultura. Essas comunicações, diz ele, são "canais de sentidos» (FP, 294). Não se trata de intenções declaradas, de ligações que se estabelecem pela vontade de Platão. Platão pode até não percebê-las, deixálas na obscuridade. E, no entanto, essas ligações não cessam de se operar por si mesmas: "Contra sua vontade? graças a ele? no seu texto? fora de seu texto? mas onde então? entre seu texto e a língua? para que leitor? em que momento?" (FP, 294). São questões às quais Derrida não responde, o que nos abre, evidentemente, perspectivas novas de liberdade e de interpretação. Parece que nos afastamos, assim, do logos, da verdade enunciada pelo rei-deus-pai-sol iluminado. São essas possibilidades de ligaçōes outras, de relaçōes culturais, que permitem ao filósofo francês identificar em Theuth a figura do deus egípcio Thot

Com efeito, Platão não descreve o personagem de Theuth, nem no Fedro nem na alusão que a ele faz em Filebo. Há traços marcantes da estrutura do personagem do deus Theuth / Thot, como as oposições upalavra / escrita, vida / morte, pai / filho, mestre / escravo, primeiro / segundo, filho legítimo / filho bastardo, alma / corpo, dentro / fora, bem / mal, seriedade / jogo, dia / noite, sol / lua" que «dominam igualmente e segundo as mesmas configurações as mitologias egípcia, babilônica e assíria» (FP, 284), além de outras, com certeza. Da mesma forma que Theuth submete-se a Tamus e acata seu julgamento, Thot é um deus submisso, filho de Rê, deus-sol, criador, que gera através do verbo, da palavra. Há, portanto, no diálogo dos mitos e das culturas, um deslocamento que se efetiva e que nos permite ler em Theuth os traços de Thot: na doutrina de Mênfis, por exemplo, Thot é quem executa, através da língua, o projeto criador de Hórus, variante do deus Rê. Evocando a autoridade dos estudos de Jacques Vandier em La religion égyptienne (Paris, P.U.F, 1949), Derrida cita : «esses dois deuses [Hórus e Thot] estariam associados no ato criador, Hórus representando o pensamento que concebe, e Thot, a palavra que executa» (FP, 389).

Continuando a refletir sobre o sentido de phármakon, Jacques Derrida refere-se à tradução da palavra por remédio, que deixa, assim, de acentuar o outro pólo de sentido que remete para a idéia de veneno. Para ele, a tradução não é inexata. Naquele momento, Thot desejava sobretudo, ao apresentar a oferenda a Tamus, fazer esquecer a ambigüidade dos sentidos a fim de que seu phármakon fosse aceito pelo Rei. Trazia-lhe um produto medicinal benéfico, que repara, revigora a memória, aumenta o saber e combate o esquecimento. Mas o que é interessante é que, no texto grego, o discurso de Thot e o de Tamus formam um jogo, 
confrontando-se, produzindo ambigüidade, o que não acontece com o texto francês. A tradução remédio, ao contrário do que aconteceria com droga ou produto medicinal, abole a possibilidade de outras significações que afloram, evidentemente, na língua grega.

Uma tal tradução destrói sobretudo o que chamaremos adiante de escritura anagramática de Platão, interrompendo as relações que aí se tecem entre diferentes funções da mesma palavra em diferentes lugares, relações virtuais mas necessariamente «citacionais».(FP, 297)

Que significa o «jogo citacional" senão o jogo do phármakonremédio que não pode existir sem evocar o phármakon-veneno?

Em ensaio de 1910, intitulado «O duplo sentido antitético das palavras primitivas", Freud, ao analisar o comportamento do sonho em relação à antítese e à contradição, cita o trabalho do filólogo $\mathrm{K}$. Abel, publicado em 1884, que aponta, na língua egípcia, «certo número de palavras com dois significados, um dos quais é precisamente a antítese do outro", palavras que significam ao mesmo tempo forte e débil, mandar e obedecer, ou palavras compostas como velho-jovem, longe-perto, fora-dentro, entre outras.

A escritura desliza sempre, furta-se sempre ao sentido único diz tudo sem afirmar nada, diz o mesmo para afirmar o outro.

Vejam, pois, a importância desse phármakon que não só opõe a escrita à palavra do rei, mas introduz a ambigüidade, o jogo de sentidos, a possibilidade de outras leituras. É essa, talvez, a questão fulcral da visão de Derrida, a questão do jogo citacional. E, aqui, caberia uma crítica a meu próprio texto.Venho procurando, de forma didática, traduzir em meu texto o termo écriture, no sentido de transcrição gráfica da fala, por escrita, reservando o termo escritura, que ainda não explorei, para traduzir a écriture enquanto phármakon, enquanto suplemento, jogo de relaçōes sempre aberto que anula a dicotomia e permite deslizar de um sentido a outro. Derrida utiliza, pois, écriture com duplo sentido, deixando ao leitor a tarefa de jogar com os sentidos. Por que razão, portanto, deveria eu inibir a força do phármakon, já que é na ambigüidade que reside sua ação? A decisão de neutralizar o jogo citacional implicou o rebaixamento da escritura em favor da phoné, decisão que decide o significado de um elemento cuja propriedade é ser indecidivel. A palavra escritura deve, portanto, também ser indecidivel, pois os dois sentidos se acham intimamente vinculados: é do seu poder de reproduzir a fala (enquanto escrita) que se aproveita para transgredi-la (enquanto escritura). Ou até mesmo para matá-la. Passo, assim, doravante, a utilizar a palavra escritura, fruindo também eu de tal ambigüidade. De uma ambigüidade fatal, que pode matar o sentido, propondo outros em seu lugar.

Aí inscreve-se, pois, o lado negativo da escritura na visão de Tamus: «a escritura é essencialmente má, exterior à memória, produtora não de ciência mas de opinião, não de verdade mas de aparência. $O$ phármakon produz o jogo da aparência em favor do qual se faz passar por verdade»(FP, 304)

Mas Derrida acentua logo de imediato o caráter positivo do movimento escritural:

E se viéssemos a pensar que algo como o phármakon - ou a escritura longe de ser dominado por oposiçōes [dicotômicas], abre-lhes possibilidades sem nelas se deixar encerrar; e se viéssemos a pensa que é somente a partir de algo tal qual a escritura - ou o phármakon que se pode anunciar a estranha diferença entre o dentro e for por conseguinte, viéssemos a pensar que a escritura como phármakon não se deixa simplesmente atribuir um lugar naquilo que ela situa, não se deixa conceber através de conceitos que se decidem a partir dela, [...], seria necessário, então, submeter a estranhos movimentos o que não se poderia nem mais chamar simplesmente lógica ou discurso. (FP, 305)

Eis como o Glossário de Derrida, organizado por Silviano Santiago, sintetiza o papel do phármakon:

O phármakon, a anti-substância, sem essência, impróprio, não-idêntico a si, só pode ser visto na gráfica do suplemento. [...] Pela capacidade contida no phármakon de se fazer passar de um significado a outro, por sua reversibilidade original é que Sócrates vai reintroduzi-lo no Fédon, como filtro do conhecimento, contraveneno, antídoto dialética. A farmácia socrática corresponde à operação do exorcismo: espanta os fantasmas que aterrorizam o indivíduo. Póe em fuga medo da morte. Repele os falsos discursos, sofística. ${ }^{6}$

Tal é a escritura: questão de vida ou de morte. Remédio ou veneno; garante a memória da palavra do outro e ao mesmo tempo a destrói. Tal é o conceito de desconstrução que aprendemos na obra de Derrida. Tal é a leitura desconstrutora que faz do Fedro de Platão: depois de apontar 
o processo de centramento na fala, no logos, na presença do pai, que rejeita e menospreza a escritura, Derrida coloca em realce, na outra face do phármakon, uma força perigosa, que, ao colocar em risco a verdade única a palavra do Pai, abre espaço para o diálogo, para a dialética, para a diferenciação das línguas, contra a autoridade do sentido, contra a história de um significado transcendental.

A escritura é parricida. Toma o lugar do Pai, abafa-lhe a voz, e liberta os significados. Em magnífico artigo, intitulado "A morte do autor", Roland Barthes discorre sobre esse poder da escritura, a qual define como segue: «A escritura é esse neutro, esse compósito, esse oblíquo onde o sujeito escapa, o preto-e-branco onde se vem perder toda identidade, a começar mesmo pela do corpo que escreven.' Donde, a escritura é órfã. Nela a paternidade perde sua identidade. E, mais adiante, continua Barthes:

Sabemos agora que um texto não é feito de uma linha de palavras, que produzem um sentido único, de alguma forma teológico (que seria a "mensagem» do Autor-Deus), mas um espaço de dimensões múltiplas, onde se reúnem e se contestam escrituras variadas, nenhuma das quais traz a marca da origem: o texto é um tecido de citações, provindas de milhares de focos da cultura.

A escritura é esse perigoso suplemento. Jean Jacques Rousseau, que escreveu o Essai sur l'origine des langues, não desconhece esse perigo. Eis aqui o que diz nas Confissões: "Todos os papéis que havia reunido para suprir a minha falta de memória e guiar-me nessa empresa, se caírem em outras mãos, jamais voltarão às minhas.."

Voltamos, assim, ao nosso ponto de partida. Rousseau, como Platão, não esconde seu medo da escritura. Talvez, agora, depois de analisarmos o phármakon, possamos melhor interpretar essas duas atitudes. $\mathrm{Na}$ realidade, o trecho da carta de Platão parece significar que está perfeitamente consciente do papel da escritura-phármakon. Separada de seu emissor, a palavra segue os rumos que a escritura lhe traça: propóe outros sentidos, é remédio e ao mesmo tempo veneno, entra em jogo - illudere condensando no seu bojo inúmeras citações, numerosas referências a outras culturas, outros mitos, outros mundos, faz-se palimpsesto, cadinho de misturas, farmácia de muitos poderes. A palavra se deixa interpretar. E, na

\section{BARTHES, 1984. p. 61.}

8. Idem. p. 65.

9. Apud DERRIDA, 1967. p. 203. interpretação, faz-se jogo. Assume a paixão de Dioniso em detrimento do equilíbrio de Apolo. E faz-se festa, orgia-desvio da escritura. A escritura é transgressão: phármakon-veneno. É como Eurídice após a transgressão de Orfeu. Não a Eurídice que, com a permissão dos deuses, volta à luz, clara, exposta ao olhar de todos, como a prova do cumprimento da palavra divina: Eurídice-luz, logos, verdade. A escritura como phármakon é Eurídice tornada noite, oculta, enigmática, fruto da transgressão do olhar de Orfeu. A que năo revela mais a misericórdia dos deuses, mas a que relembra a falta do poeta. Aquela Eurídice que provoca o desejo, que faz sonhar, que tudo pode significar, porque deixou de ser a clara luz sem mistério algum. É aquela que, paradoxalmente, escapando ao domínio público, torna-se texto, torna-se, não mais logos, mas mito: mito cantado, contado, relido. Escritura.

Quando Platão teme que o texto escrito caia no domínio público, teme que os significantes escapem ao pai e que o recontar dos contos contem uma outra história. E, como naquele jogo infantil de repetir a frase no ouvido do outro até que se deforme inteiramente, o que teme o filósofo na sua vasta ciência é aquilo que nos ensina a sabedoria popular: quem conta um conto aumenta um ponto. Daí, a defesa. Daí, a aura sagrada que envolve a palavra. Daí, a proteção divina do verbo do Pai. O centramento. O sacrário. A redução de tudo a um ponto: a uma origem. Assim é possível preservar a origem e a verdade.

Com efeito, tal verdade e tal origem năo podem ser preservadas. O phármakon - na sua dupla potencialidade - as destrói, e permite-nos escrever uma outra história.

O advento da escritura é o advento do jogo; o jogo hoje entrega-se a si mesmo, apagando o limite a partir do qual acreditou-se poder regular a circulação dos signos, arrastando com ele todos os significados seguros, reduzindo todas as áreas de segurança, todos os abrigos de quem não podia jogar, tudo o que vigiava o campo da linguagem. ${ }^{10}$

"Sócrates, aquele que não escreve». No Fédon, o phármakion aparece como o filtro do conhecimento, antídoto, dialética.

É esse phármakon invertido, agora dialético, que vai penetrar na alma daqueles que ouvem Sócrates, sob a forma de belos discursos, caminho para a sabedoria. O logos socrático, enquanto manteia (pharmakeus),

10. DERRIDA, 1967. 
palavra divinatória, transformadora, fundamenta em filosofia, em episteme, uma prática empírica. Tal atitude já havia sido prenunciada no início do Fedro, quando Sócrates denuncia a insuficiência do conhecimento em favor do preceito délfico "conhece-te a ti mesmo"."

O logos de Sócrates não é aletheia: é manteia. Não impõe um sentido. É dialético: abre-se à discussão e ao diálogo, aos Diálogos que Platão soube tão bem reproduzir. É jogo - descoberta de um saber empírico, jogo da maiêutica - jogo sedutor de escritura.

No diálogo das obras, a escritura permite reler e reinventar o passado. Quem poderá conhecer o sentido das obras que nos precedem? Quem poderá conhecer a «verdade»? Quem terá ouvido a palavra do deuspai-sol? Buscar a verdade absoluta é tarefa fadada ao insucesso. Fixar um sentido único para as palavras seria abolir a possibilidade do diálogo. Privilegiar a palavra do Pai seria negar o poder de significação da escritura. A releitura da palavra escrita redescobre o mundo e reatualiza a cosmogonia.

Para preservar a memória, Thot inventou a escritura, tal qual inventou o jogo. Derrida relê Platão, cita seus sentidos nos textos que escreve. E, dessa forma, participa de um jogo sempre arriscado de redizer o que foi dito e deixar que outros o tornem a dizer.

O texto faz-se, portanto, risco. Risco, em sentido duplo: traço e perigo. Sem relação semântica nem etimológica no léxico. Aqui, porém, por mim colocados em confronto - espelhados em «miragem semântica", para seguir o ensinamento de Derrida, onde o significante de um ecoa e se reflete no significante do outro. Onde o risco da escrita torna-se o risco da escritura.

\section{REFERÊNCIAS BIBLIOGRÁFICAS}

BARTHES, Rolond. Le bruissement de la langue. Poris: Sevil, 1984 DERRIDA, Jocques. De la gramatologie. Poris: Minuit, 1967. Lo dissémination. Poris: Sevil, 1972.

PLTON. Phedre. Ir. Luc Brisson. Poris: Flommorion, 1989.
SANTIAGO, Silviono (Org.). Glossóno de Derrida. Rio de Janeiro: Francisco Alves, 1976.

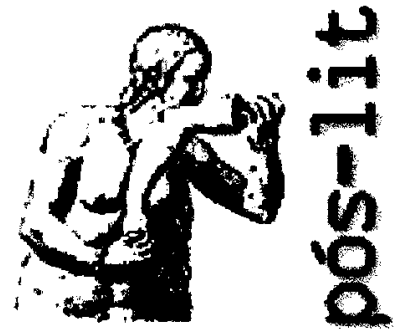

\section{Programa de Pós-Graduação em Letras: Estudos Literários da Faculdade de Letras da UFMG}

\author{
Artigo disponível em \\ http://www.letras.ufmg.br/poslit
}

